\title{
HCI and the Educational Technology Revolution \#HCIEd2018
}

\author{
A workshop on video-making for teaching and learning Human-Computer Interaction
}

\author{
Adriana Wilde \\ University of St Andrews \\ School of Computer Science \\ United Kingdom \\ agw5@st-andrews.ac.uk
}

\author{
Anna Vasilchenko \\ Newcastle University \\ School of Computing \\ United Kingdom \\ a.vasilchenko@newcastle.ac.uk
}

\author{
Alan Dix \\ Swansea University \\ Computational Foundry \\ United Kingdom \\ alan@hcibook.com
}

\begin{abstract}
Over the years, the HCI Educators series has studied a number of challenges for the teaching and learning of Human-Computer Interaction at a time of radical educational change. Though video has historically played an important part on the teaching and development of HCI, only recently video-making and editing technologies have become accessible in an unprecedented way, allowing students to become proficient video "prosumers" (producers and consumers). Further, there are numerous educational gains to be had through these technologies. Through a very interactive workshop we explore how can video be used in practice to leverage skills and foster creativity whilst facilitating knowledge acquisition.
\end{abstract}

\section{CCS CONCEPTS}

- Human-centered computing $\rightarrow$ Human computer interaction (HCI) - Human-centered computing $\rightarrow$ Visualization • Social and professional topics $\rightarrow$ Computing education

\section{KEYWORDS}

HCI education, video making, assessment, curriculum design

ACM Reference format:

A. Wilde, A. Vasilchenko and A. Dix. 2018. HCI and the Educational Technology Revolution \#HCIEd2018 - A workshop on video-making for teaching and learning Human-Computer Interaction. In Proceedings of ACM International Conference on Advanced Visual Interfaces, Castiglione della Pescaia, Grossetto, Italy. May 2018 (AVI 2018), 3 pages. https://doi.org/10.1145/3206505.3206600

\section{INTRODUCTION}

Over the years, the HCI Educators series has studied a number of challenges for the teaching and learning of Human-Computer

Permission to make digital or hard copies of part or all of this work for personal or classroom use is granted without fee provided that copies are not made or distributed for profit or commercial advantage and that copies bear this notice and the full citation on the first page. Copyrights for third-party components of this work must be honored. For all other uses, contact the Owner/Author.

AVI '18, May 29-June 1, 2018, Castiglione della Pescaia, Italy

(C) 2018 Copyright is held by the owner/author(s).

ACM ISBN 978-1-4503-5616-9/18/05.

https://doi.org/10.1145/3206505.3206600
Interaction at a time of radical educational change. With every new edition of the workshop, practitioners have explored various aspects of this change, from MOOCs to peer learning, the use of Open Educational Resources, the opportunities (and limitations!) of blended learning, as well as the use of learning analytics. One important common medium for each of these educational innovations is video.

Though video has been long used by educators for delivering content [1], only recently video-making and editing technologies have become accessible in an unprecedented way, meaning that many students come to universities as proficient producers as well as consumers of video content [10]. Further, it has been shown that video can be used to good effect to encourage reflective learning [2], and various tools have been developed for the critical analysis of videos in HCI education [3], with interesting unintended learning outcomes for video-authoring students, such as an increased media literacy [4]. We posit that there is a critical mass of HCI educators willing to share their experiences in using video as an assessment tool $[5,6,11]$, so this year's focus is on the use of video in $\mathrm{HCI}$ education.

\section{EDUCATION IS (STILL!) CHANGING}

As we have pointed out earlier, though educational technology has a long pedigree, the last few years continue to see dramatic changes, such as the rise and institutionalisation of Massive Open Online Courses (MOOCs), Small Private Online Courses (SPOCs), and other web-based initiatives. Classrooms have also been transformed with growing use of mobile devices and forms of flipped classroom; and educational progress and engagement has been increasingly measured leading to institutional and individual learning analytics. Further, students are increasingly becoming cocreators of content and it is imperative to channel, and capitalise on, this skillset to encourage learning through the medium of video.

The HCI community has been in many ways, the logical pioneer of the use of video. Indeed, video has been used in HCI as early as in the 1960s, ever since the first video-game was created [7], as it is the natural medium to showcase state-of-the-art visualisations. In particular, thanks to the affordances of the video medium (e.g. reproducibility, pausing, rewinding and fastforwarding), it is ideally suited for learning visual concepts and honing on design skills such as those we expect our graduates to acquire. 
We ask the HCI community how can video be used to leverage skills and foster creativity whilst facilitating knowledge acquisition? How is video used in practice by educators and students for learning, assessment and feedback?

\section{WORKSHOP GOALS}

Participants of this workshop will explore these issues in HumanComputer Interaction education in a number of ways:

- Discussing opportunities and challenges that are specific for use of video in teaching and learning HCI

- Connecting practitioners to share contextual experiences in using video in HCI education

- Discussing curriculum design implications to include the use of technology

- Generating a collection of good practice "tips" and lessons learned for the benefit of those willing to start using video in learning, assessment and feedback for HCI specifically, and seek to disseminate them afterwards in a practitioners' focused publication.

- Reconciling practice-based with theoretical approaches to construct a vision of the current state-of-the-art learning technologies in HCI to then identifying future challenges.

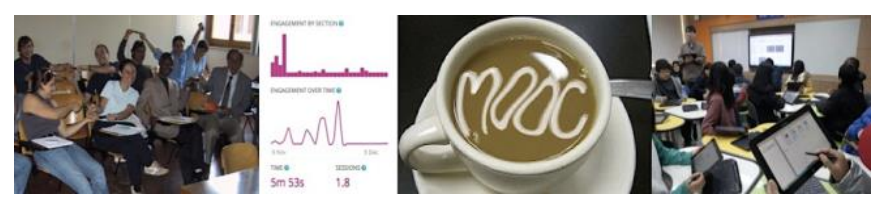

Figure 1: Building on HCI Educators' workshop \#HCIEd2016 http://hcied.org/

\section{WORKSHOP ACTIVITIES}

There will be some pre-workshop activities, which, as in previous years, will involve a collaborative peer review of the selected contributions, which can be submitted online via EasyChair as an extended abstract, all in English language, not exceeding four (4) pages in length following the ACM SIGCHI template.

During the workshop itself, very short presentations will be given by all participants as a manner of mutual introductions and to narrow the scope of the day. This is followed by longer presentations of selected case studies around the following themes:

Theme I: Students as video consumers (video for instruction)

- It's Me or the Video: can videos substitute for lectures in the flipped classroom? (Chris Evans)

Theme II: Students as producers (video for assessment)

- Video as a deliverable: practical challenges and opportunities in assessment and feedback (Adriana Wilde and Stephen Snow)

- $\quad$ Literacies for video-making: experiences from teaching Ubicomp (Anna Vasilchenko)

The main activity will be a world-café activity [8], by brainstorming rapidly-rotating groups leading to posters created with practical tips in using video in HCI education with a focus on assessment and feedback, followed by a consolidation session in which participants summarise their recommendations. These resources will be made available to the wider community after the event (see Section 3).

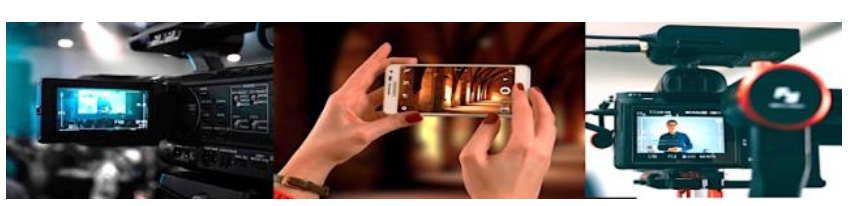

Figure 2: HCI Educators' workshop \#HCIEd 2018

http://alandix.com/hcied2018/

\section{CALL FOR PARTICIPATION STRATEGY}

The strategy to reach out for potential participants to the workshop would be primarily through the extended professional networks of the Workshop Chairs (see Section 6), including relevant social media channels (Twitter, Facebook). Also, we intend to invite previous participants of the \#HCIEd. The workshop's intended audience are HCI educators, which greatly overlaps the Advanced Visual Interfaces (AVI) community.

\section{ON THE WORKSHOP CHAIRS}

\subsection{Adriana Wilde}

Adriana is an Associate Lecturer at the University of St Andrews, pursuing a part-time $\mathrm{PhD}$ in Computer Science under the supervision of Ed Zaluska and Dave Millard at the University of Southampton, focusing on factors related to student success in Higher Education and MOOCs, as well as the use of technology for teaching, assessment and feedback.

Adriana's background is multidisciplinary but with a strong dual interest in education and technology. After her B.CompSc.(Hons) degree at the Universidad Central de Venezuela, Adriana became a lecturer there. She also holds several teaching qualifications from the UK, including a PGCE in Post-Compulsory Education and Training, and has taught in diverse educational environments, including primary schools, further education colleges as well as universities. Adriana has also been awarded an MSc in Computer Science by the Universities of Berne, Fribourg and Neuchâtel in Switzerland (with specialism in Distributed Systems with a minor in Education), and was a Mayflower Scholar for Electronics and Computer Science at the University of Southampton, becoming a PhD candidate and a Teaching Fellow in the same department.

Adriana's workshop organization experience has included the EMOOCs 2017 workshop "Leveraging Learning Analytics to Identify and Overcome Barriers to MOOCs in a Foreign Language". Adriana has also co-organized (with Jess Spurrell) the HEA workshop "Discovering Networks for Culture Change: Lessons from One University's Approach to Tackling the STEM 'Diversity Deficit", in 2017; and the HEA workshop "STEM Pedagogies: Best practice considerations", in 2016. She was the 
academic lead for the smallpeice/ARM Computing and Microelectronics Summer School in 2016 and 2017 in Southampton.

\subsection{Anna Vasilchenko}

Anna is a postgraduate researcher based in Open Lab at Newcastle University. She works on innovative methods of teaching and learning for STEM subjects in higher education, under the supervision of Marie Devlin, Madeline Balaam, Anne Preston, and Patrick Olivier. Anna's specific focus is on student-generated content and blended learning (such as Flipped Classroom and SelfOrganized Learning Environment) which are built around ideas of 'learning through making' and 'peer learning'. Her research objective is to design a new pedagogical model to ease the transition from traditional to flipped classroom teaching for instructors, whilst enhancing student learning experience through the production of digital learning materials.

Anna's background is also multidisciplinary with a persistent focus on higher education. Having completed a BA in Mass Communication and Journalism at American University of Central Asia, she then worked as a Public Relations practitioner for universities in Kyrgyzstan and Russia. Later she obtained an MEd in Leadership and Management in higher education from Newcastle University, where she's currently pursuing her $\mathrm{PhD}$.

Anna has an extensive experience in organizing and managing various events. This includes voluntary work for youth NGO in Kyrgyzstan, where she organized a number of charity events. Also in Kyrgyzstan back in 2002, Anna was a member in organizing committee for the first "Gender development in Kyrgyzstan" conference. More recently, while working in European University at St. Petersburg, Russia, she was a lead administrator (in a team of 5) for several successful international summer schools.

\subsection{Alan Dix}

Alan is the Director for the Computational Foundry at Swansea University. He has worked in human-computer interaction research since the mid 1980s, is the author of one of the major international textbooks on HCI [9] and author of approximately 500 research publications covering topics from formal methods to creativity. In 2013 he produced an HCI MOOC that is now hosted at InteractionDesign.org and the materials reused for flip class teaching. In the same year he walked 1000 miles round the coast of Wales; the outcomes of which have included a case study of the educational use of the data gathered during the walk in the Open Knowledge Foundation book on "Open Data as Open Educational Resources".

Alan's workshop and conference organisation has included the AVI 2016 workshop on HCI and the Educational Technology Revolution \#HCIEd, predecessor of the one hereby proposed. Alan also organised the AVI 2012 workshop on "Infrastructure and design challenges of coupled display visual interfaces", a 2012 Dagstuhl seminar on "Interaction Beyond the Desktop", a workshop (with Silvia Gabrielli) on "Learning and HumanComputer Interaction" at Interact 2005, chairing the British HCI conference in 1995 and HCIEducators conference in 2007, and an occasional conference series on Physicality. He also runs the twice- yearly workshop "Tiree Tech Wave" encouraging researchers, technologists, artists and makers to experience and think about the design issues of marginal communities.

\section{REFERENCES}

1. Jason Day and Jim Foley. 2006. Evaluating web lectures: a case study from HCI. In Proceedings of CHI '06 extended abstracts on Human factors in computing systems - CHI EA '06, 195-200. https://doi.org/10.1145/1125451.1125493

2. Dragan Gašević, Negin Mirriahi, and Shane Dawson. 2014. Analytics of the effects of video use and instruction to support reflective learning. In Proceedings of the fourth international conference on learning analytics and Knowledge. ACM, 2014. https://doi.org/10.1145/2567574.2567590

3. Vikash Singh, Sarah Abdellahi, Mary Lou Maher, and Celine Latulipe. 2016. The Video Collaboratory as a Learning Environment. In Proceedings of the 47th ACM Technical Symposium on Computing Science Education - SIGCSE '16, 352-357. https://doi.org/10.1145/2839509.2844588

4. Anna Vasilchenko, David Philip Green, Haneen Qarabash, Anne Preston, Tom Bartindale, and Madeline Balaam. 2017. Media Literacy as a By-Product of Collaborative Video Production by CS Students. In the 22nd Annual Conference on Innovation and Technology in Computer Science Education. https://doi.org/10.1145/3059009.3059047

5. Adriana Wilde and Stephen Snow. 2018. Addressing challenges in assessing Human-Computer Interaction at scale. In the Computing Education Practice conference, 11-12 January, Durham, UK.

http://community.dur.ac.uk/cep.conference/2018/programme. php\#abstract13

6. Stephen Snow and Adriana Wilde. 2017. Video as an assessment tool: COMP2213. In What Works in Assessment and Feedback: Simply Better, 2017.

7. Brad A. Myers. 1998. A brief history of human-computer interaction technology. interactions 5, no. 2, 44-54.

8. Rachel Aldred. 2011. From community participation to organizational therapy? World Cafe and Appreciative Inquiry as research methods. Community Development Journal 46.1: $57-71$.

9. Alan Dix, Janet E. Finaly, Gregory D. Abowd, and Russell Beale. 1993, 1998, 2004. Human Computer Interaction. Pearson Prentice Hall.

10. Catherine Mcloughlin and Mark J W Lee. 2008. The Three P's of Pedagogy for the Networked Society. International Journal of Teaching and Learning in Higher Education 20, 1: 10-27. https://doi.org/10.1017/S1537592709991423

11. Anna Vasilchenko, Adriana Wilde, Stephen Snow, Madeline Balaam, Marie Devlin. 2018. Video Coursework: Opportunity \& Challenge for HCI Education. In Proceedings of the 2018 ACM International Conference on Advanced Visual Interfaces. https://doi.org/10.1145/3206505.3206596 